\title{
Primary Frequency Support from Offshore Wind Power Plants Connected to HVDC Grids
}

Bidadfar, Ali; Saborío-Romano, Oscar; Sakamuri, Jayachandra Naidu; Altin, Müfit; Cutululis, Nicolaos Antonio; Sørensen, Poul E.

\section{Published in:}

Proceedings of the 2019 IEEE Milan PowerTech

Link to article, DOI:

10.1109/PTC.2019.8810820

Publication date:

2019

Document Version

Peer reviewed version

Link back to DTU Orbit

Citation (APA):

Bidadfar, A., Saborío-Romano, O., Sakamuri, J. N., Altin, M., Cutululis, N. A., \& Sørensen, P. E. (2019). Primary Frequency Support from Offshore Wind Power Plants Connected to HVDC Grids. In Proceedings of the 2019 IEEE Milan PowerTech (pp. 1-6). IEEE. Proceedings of the IEEE https://doi.org/10.1109/PTC.2019.8810820

\section{General rights}

Copyright and moral rights for the publications made accessible in the public portal are retained by the authors and/or other copyright owners and it is a condition of accessing publications that users recognise and abide by the legal requirements associated with these rights.

- Users may download and print one copy of any publication from the public portal for the purpose of private study or research.

- You may not further distribute the material or use it for any profit-making activity or commercial gain

- You may freely distribute the URL identifying the publication in the public portal 


\title{
Primary Frequency Support from Offshore Wind Power Plants Connected to HVDC Grids
}

\author{
Ali Bidadfar, Oscar Saborío-Romano, Jayachandra N. Sakamuri, \\ Müfit Altin, Nicolaos A. Cutululis, Poul E. Sørensen \\ Department of Wind Energy \\ Technical University of Denmark \\ Risø Campus, Denmark \\ Email: abid@dtu.dk
}

\begin{abstract}
Contribution to the power systems' frequency support is expected to be one of the essential ancillary services that wind power plants (WPPs) shall provide. The high-voltage DC (HVDC) connected offshore WPPs may provide this service with and without using fast communication links between onshore and offshore. In the case of offshore HVDC grid, implementing the communication-less frequency support is challenging. Although it increases the reliability of the frequency control, among other challenges, it is not straightforward to comply with relevant grid code requirements. In this paper, this issue is mathematically described and a static model is developed to calculate the deviation of various electrical parameters of an HVDC grid in case of frequency drop on the land ac systems. A solution for the aforementioned problem is presented and its associated concerns are addressed. The study is verified by simulations of a four terminals de grid with two offshore WPPs and two inland ac systems.
\end{abstract}

Index Terms-Droop control, frequency support, HVDC, offshore wind.

\section{INTRODUCTION}

The installations of wind power plants (WPPs) with variable-speed wind turbines are growing rapidly worldwide and it is expected that a large portion of conventional power plants to be replaced with wind (and solar) power. Since these type of generations do not inherently show inertia against an immediate frequency drift, future power systems can be prone to instability under circumstances such as sudden change of load and-or generation.

It has been studied that variable-speed wind turbines with supplementary controllers can provide frequency support by changing their output power in case of frequency deviations [1]-[4]. Implementing such supportive control is relatively straightforward for onshore WPPs and ac connected offshore wind power plants (OWPPs), because, the respect controller can sense the frequency deviation locally and regulate the wind turbine's output power. However, in the case of highvoltage direct-current (HVDC) connected OWPPs the supplementary controller of offshore wind turbines need the onshore frequency deviation to be communicated to the offshore using fast communication links. It has been shown in [5] that dc connected OWPPs can implement frequency support without

This work has received funding from the European Union's Horizon 2020 research and innovation programme under grant agreement No 691714. using fast communication link (called communication-less in this paper). In this method, droop controls are used to change the dc-link voltage and offshore frequency in such a way that the offshore frequency mirrors the onshore's. Therefore, the wind turbines in OWPPs can contribute in frequency support with the same as those in onshore.

Offshore HVDC grids are conceived to present more reliable and economical solutions for transferring more offshore wind power to inland ac systems. There are different ways of controlling the power flow among the converters of an HVDC grid [6]. The dc-link voltage droop control, also called autonomous power-sharing, is the most promising approach since the dclink voltage is controlled by more than one converter, and therefore, the grid operation can be more secure.

The HVDC grids can also contribute to the frequency support by extracting more power from OWPPs and-or using power reserve capacities of other ac systems. In the former, the required power can be provided from wind turbines' inertial capacity [7], and-or headroom capacity of down-regulated available wind power [8]-[15]. Inspiring from the droop control of HVDC grids, the communication-less method for frequency control method is one of the solution for the HVDC grids. However, for communication-less frequency control the HVDC grids with voltage droop control is not very efficient. In this scheme, the frequency and voltage droop controls can interact with each other, and consequently, the host ac system - the one in need of frequency support—cannot receive the required amount of power [12].

In this paper, the droop interactions and their impact on the communication-less frequency support from HVDC grids are mathematically described. It is shown that the compensation method proposed in [12] to overcome the droop interaction effects on the frequency support can be challenging if there are more than one inland ac systems connected to an HVDC grid. A static block-diagram is proposed to calculate the different electrical parameters such as frequency, dc-link voltage and active power in different parts of an HVDC grid with frequency support capability. The model also simplifies the calculation of compensation factors which are needed in the case of communication-less frequency support.

The paper is organized as follows. In Section II the offshore HVDC grid configuration and controllers of converters and 


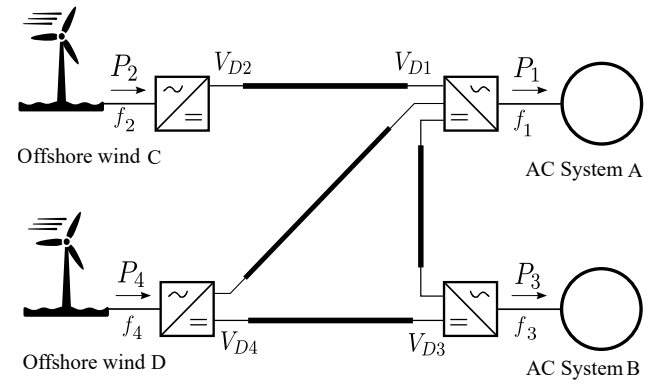

Fig. 1. HVDC grid connecting two OWPPs to two onshore ac power systems.

wind turbines, required to implement the communication-less frequency support, are presented. Different modes of converter operation, i.e., dc voltage droop or constant power control, are explained in Section III. Mathematical expressions of frequency support for different HVDC operation schemes is derived in Section IV and static model, useful for calculating compensation factor for communication-less method of frequency support is developed in Section V. Simulation results are presented in Section VI, and finally the paper is concluded in Section VII.

\section{HVDC TOPOLOGY AND CONVERTERS CONTROLLER}

The HVDC network model and its control and also assumptions made in modeling and simulations are presented in this section.

The de grid topology is shown in Fig. 1. It has two offshore WPPs and two onshore ac systems. Each of onshore systems is modeled as an aggregated synchronous machine equipped with a turbine and governor. An aggregated passive load is used to create the frequency event.

The onshore converters can be operated in constant power or voltage, or even droop control modes. The droop controller of HVDC converter is shown in Fig. 2, and it is responsible for active power balance in the dc grid by sharing the dc grid voltage control. The frequency droop control is also included in Fig. 2 which generates additional active power reference $\left(\Delta P_{f}\right)$ to the HVDC converter according to the onshore AC grid frequency deviations. The frequency and active power biases (inverse of droop) are indicated by $k_{f}$ and $k_{p}$. The subscripts for all parameters are numbered based on the number of onshore converters, which can be 1 or 3 . The blocks $\mathrm{CC}$ and Q-V stand for current controller and reactive and/or ac voltage controller respectively. The control scheme of offshore HVDC converters is shown in Fig. 3. These converters do grid forming for offshore ac networks. The voltage droop control is included in the controller to change the offshore ac frequency in case of dc-link voltage deviations. The voltage bias is shown as $k_{v}$. The subscripts of parameters of this controller can be either 2 or 4 depending on the number of offshore converter.

The offshore systems are modelled as aggregated IEC fullyrated (Type-4) wind turbines based on the aggregation method given in [16]. The active power control of offshore WTs is shown in Fig. 4. The frequency deviation changes the turbine's output power. In the figure the frequency derivative is also

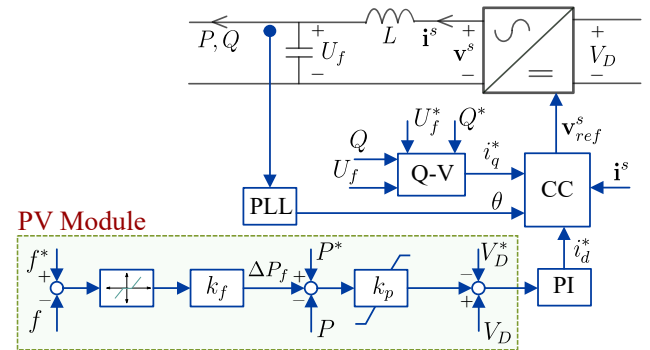

Fig. 2. Onshore converters' control system including frequency and power droops respectively with $k_{f}$ and $k_{p}$ gains.

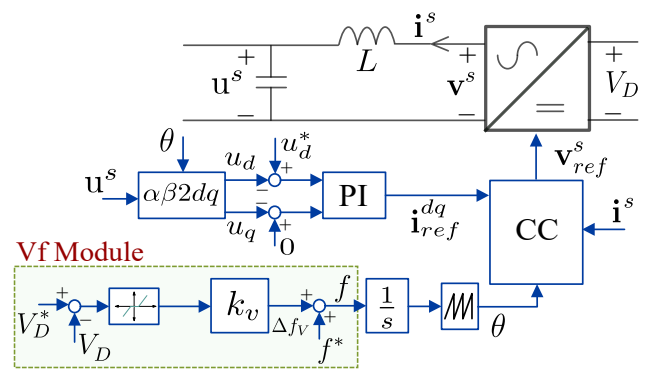

Fig. 3. Offshore converters' control system including frequency droop with $k_{v}$ gain.

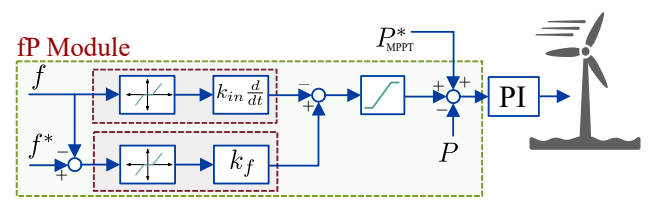

Fig. 4. Offshore Wind turbines control with frequency droop.

shown which is activated in case of inertia control. However, the primary frequency control is the main focus of this paper and only the proportional gain i.e., $k_{f}$ is considered in the modelings and activated in simulations.

Assumptions made in this paper are: the converters and dc-link losses are neglected; the offshore WPPs have enough headroom power to supply in case of frequency support; the system operators of onshore systems agree to contribute in the frequency support of each network.

\section{MODES OF HVDC GRID OPERATION}

In a point-to-point offshore HVDC connection, normally the onshore converter maintains the dc-link voltage, and offshore converter operates as a grid forming for offshore ac grid. The active power of the link is controlled by offshore wind turbines. Similarly, in an offshore HVDC network, the ac grid forming is fulfilled by offshore converters. The onshore converters operation depends on the chosen control method which can be master-slave, voltage droop or voltage margin control [17]. For the frequency support study, two different types of control are taken into account. First, the converter 1, in Fig. 1, operates with voltage control and converter 3 on active power. However, to implement the communicationless frequency support from offshore WPPs, converter 1 must be on voltage droop control model. This fact is shown in 
Section IV. Second, both onshore converters operate with voltage droop control. Therefore there will be an autonomous power-sharing among onshore converters. The control mode of onshore converters influences the frequency support to each of the ac systems. In the following section, this impact is mathematically described.

\section{FREQUENCY SUPPORT FROM HVDC GRIDS}

In this section, frequency support from HVDC grid, shown in Fig. 1, with and without using fast communication links is investigated. It is assumed that in the case of using communication link, the frequency support is provided only from offshore WPPs by communicating appropriate signals to both of the plants to change their active power. In the case of providing frequency support without using communication link, any onshore frequency deviation results in dc-link voltage change, via the PV Module shown in Fig. 2. The dc-link voltage change is sensed by the offshore HVDC converter and the offshore ac frequency changes accordingly as shown in the Vf Module in Fig. 3. Finally, the offshore wind turbines measure the frequency deviation and respond with changing their output power using the droop control in fP Module shown in Fig. 4. The other onshore HVDC converter in droop control naturally modifies its active power output to control the dc-link voltage.

The steady-state operation after a frequency disturbance on each of the shore systems is analyzed, and a relation between frequency deviation and HVDC power change is derived. It is assumed that when the steady-state reaches, the primary frequency support from the local governor and offshore WPPs has already been provided. The investigations aim to assess the impact of the communication-less method on the frequency support from WPPs.

\section{A. Frequency Support with Master-Slave Control}

It is assumed that the system A is in need of frequency support and converter 3 operates with constant power. The support is supplied from offshore WPPs, and it can be implemented using communication links between onshore A and offshore $\mathrm{C}$ and $\mathrm{D}$, or without using communication links and only by droop control.

1) Using Communication Link: The additional power, from converter A, expected by the transmission system operator (TSO) of onshore A is determined as $\Delta P_{\text {exp }}=k_{f 1} \Delta f_{1}$ in which the $k_{f 1}$ is the frequency bias. $\Delta P_{\text {exp }}$ is divided into two parts, $\Delta P_{2}$ and $\Delta P_{4}$, considering the available power of the wind farms and other constraints such as converters' limits. The signals $\Delta P_{2}$ and $\Delta P_{4}$ are respectively communicated to offshore $\mathrm{C}$ and $\mathrm{D}$, and in response, they increase their power. Since the converter 3 operates with constant power, all additional power from WPPs will be collected by converter 1 , which means this converter will supply the power that was expected by the TSO. This is challenging when implementing frequency support without using communication links.
2) Without Communication Link: Frequency support without using fast communication links is implemented via droop controls represented in Fig. 2, 3 and 4. The steady state operation after frequency deviations can be described by the input-output equations of the PV, Vf and fP Modules (shown in the control figures).

$$
\begin{aligned}
\mathrm{A} \rightarrow & V_{D 1}-V_{D 1}^{*}+k_{p 1}\left(P_{1}^{*}-P_{1}+k_{f 1}\left(f_{1}^{*}-f_{1}\right)\right)=0 \\
\mathrm{~B} \rightarrow & P_{3}^{*}-P_{3}=0 \\
\mathrm{C} \rightarrow & P_{2}^{*}-P_{2}+k_{f 2}\left(f_{2}^{*}-f_{2}\right)=0 \\
& \quad f_{2}=f_{2}^{*}+k_{v 2}\left(V_{D 2}-V_{D 2}^{*}\right) \\
\mathrm{D} \rightarrow & P_{4}^{*}-P_{4}+k_{f 4}\left(f_{4}^{*}-f_{4}\right)=0 \\
& \quad f_{4}=f_{4}^{*}+k_{v 4}\left(V_{D 4}-V_{D 4}^{*}\right)
\end{aligned}
$$

where the parameters with asterisk superscript stand for reference values which are determined from power-flow solutions. Assuming loss-less dc transmission lines, all dc-link voltages will be the same, and the power balance will be $P_{1}+P_{3}=P_{2}+P_{4}$. With this assumption, a small deviation from the equilibrium point will result in

$$
\begin{aligned}
& \mathrm{A} \rightarrow \Delta V_{D}-k_{p 1} \Delta P_{1}-k_{p 1} k_{f 1} \Delta f_{1}=0 \\
& \mathrm{~B} \rightarrow \Delta P_{3}=0 \\
& \mathrm{C} \rightarrow \Delta V_{D}+k_{p 2} \Delta P_{2}=0 \quad: \quad 1 /\left(k_{v 2} k_{f 2}\right) \\
& \mathrm{D} \rightarrow \Delta V_{D}+k_{p 4} \Delta P_{4}=0 \quad: \quad 1 /\left(k_{v 4} k_{f 4}\right)
\end{aligned}
$$

which can be compiled as

$$
\Delta P_{1}=-k_{f 1} \underbrace{\left(\frac{k_{p 1} k_{p 2}+k_{p 1} k_{p 4}}{k_{p 1} k_{p 2}+k_{p 1} k_{p 4}+k_{p 2} k_{p 4}}\right)}_{\text {Attenuation factor }} \Delta f_{1} .
$$

The attenuation factor shown in (9) is less than unity and makes the deliverable power, $\Delta P_{1}$, to onshore A less than the expected power $\Delta P_{\text {exp }}$. This may not be desirable for system operators. The power deduction can be compensated by multiplying $k_{f 1}$ by the inverse of the attenuation factor in (9). The compensation requires that onshore control knows the offshore control parameters $k_{p 2}$ and $k_{p 4}$.

The frequency support to onshore B can also be provided with or without using the communication link. In either case, the required power can be supplied to system B. However, in the former case all required power comes from WPPs and in the latter also from onshore A. Moreover in the latter case the converter 1 must be on power-voltage droop control mode. If the converter 1 controls the dc-link voltage, all the required power will be taken from system A without any change in the WPPs power.

\section{B. Frequency Support with Droop Control}

It is assumed that both of the onshore HVDC converters operate with voltage droop control and system $\mathrm{A}$ is in need of frequency support. By using communication links, all expected power can be supplied to system A. In the case of implementing the support using droop controllers (without 
communication links) the following operating equation can be written

$$
\begin{aligned}
\mathrm{A} \rightarrow & V_{D 1}-V_{D 1}^{*}+k_{p 1}\left(P_{1}^{*}-P_{1}+k_{f 1}\left(f_{1}^{*}-f_{1}\right)\right)=0 \\
\mathrm{~B} \rightarrow & V_{D 3}-V_{D 3}^{*}+k_{p 3}\left(P_{3}^{*}-P_{3}+k_{f 3}\left(f_{3}^{*}-f_{3}\right)\right)=0 \\
\mathrm{C} \rightarrow P_{2}^{*}-P_{2}+k_{f 2}\left(f_{2}^{*}-f_{2}\right)=0 & \quad f_{2}=f_{2}^{*}+k_{v 2}\left(V_{D 2}-V_{D 2}^{*}\right) \\
& \mathrm{D} \rightarrow P_{4}^{*}-P_{4}=0
\end{aligned}
$$

where for simplicity it is assumed that offshore D operates with constant power.

Any power change from HVDC converters results in primary frequency deviation on onshore ac grids. The amplitude of the frequency drift depends on the damping factor and governors setting of the shore system. For instance, the power change, $\Delta P_{3}$, on converter $\mathrm{B}$ results in

$$
\Delta f_{3}=\frac{1}{D_{3}+k_{g 3}} \Delta P_{3}, \quad k_{g 3}=1 / R_{g 3}
$$

where $R_{g 3}$ and $D_{3}$ are respectively the frequency droop of the governor and damping factor of ac system $\mathrm{B}$. The relation between power and frequency of onshore A considering (14) cab be express as

$$
\Delta P_{1}=-k_{f 1} \frac{k_{p 1} k_{p 2}+k_{p 1} k_{p 3}+\frac{k_{p 1} k_{p 3} k_{f 3}}{D_{3}+k_{g 3}}}{k_{p 1} k_{p 2}+k_{p 1} k_{p 3}+k_{p 2} k_{p 3}+\frac{\left(k_{p 1}+k_{p 2}\right) k_{p 3} k_{f 3}}{D_{3}+k_{g 3}}} \Delta f_{1}
$$

unlike (9), the (15) is more complicated and depends on the system parameters of system B, i.e., $D_{3}$ and $k_{g 3}$ which are not convenient to obtain as in practical system they are aggregated parameters representing effects of many generators, turbines, governors and loads. Therefore, implementing the compensation for this type of frequency support is challenging.

\section{HVDC Static Model For Frequency Support}

From (9) and (15) that obtaining the attenuation factor and its inverse (compensation factor) is complicated as it depends on both control parameters and operating condition. Moreover, it can be desired to calculate how much frequency deviation affects other parameters, e.g. voltage, power, and frequency of other systems. A static model, shown in Fig. 5 is developed to calculate different parameter deviation in case of frequency drift of $\Delta f_{1}$. The model can be adapted to any HVDC topology with different control strategies. Any offshore system with droop control can be added to the model like those shown as "offshore C" and "offshore D." Likewise, other onshore systems with droop control can be added like the one shown as "onshore B" in Fig. 5. The well-known Mason Gain Rule can be used for calculating the relation between parameters in the proposed model.

\section{Simulation Results}

The test system, shown in Fig. 1 has been simulated in DIgSILENT environment. Under steady-state operation, offshore WPPs C and D produce 780 and 800 MW respectively,

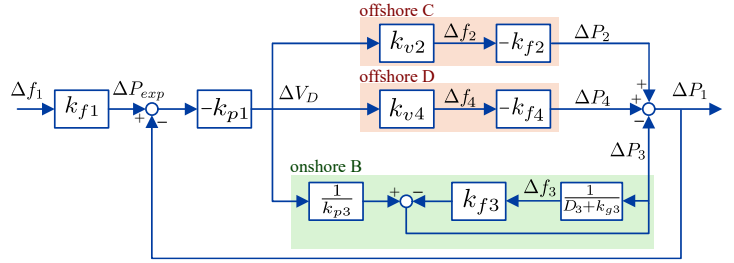

Fig. 5. HVDC static model seen from onshore A point of view.

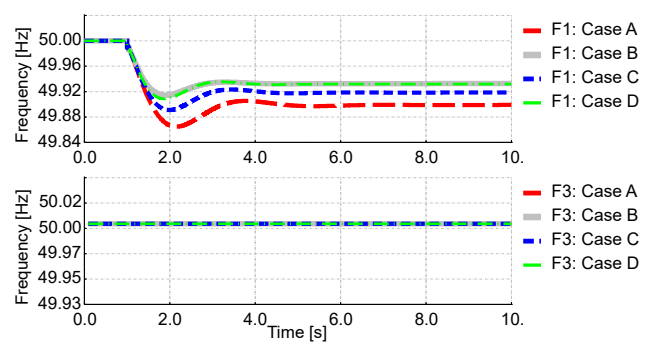

Fig. 6. Frequency of onshore ac grids when a load increases on onshore A.

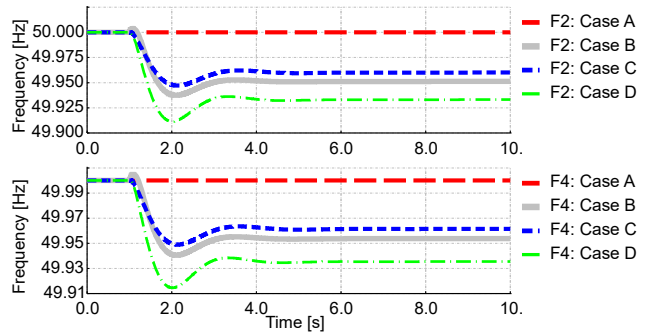

Fig. 7. Frequency of offshore ac grids when a load increases on onshore A.

and onshore A and B feed 655 and 1011 MW to their ac systems. The dc-link voltage is $640 \mathrm{kV}$ pole-to-pole. Synchronous machines, turbines, and governors of both onshore systems are similar. The inertia constant of each system is $10 \mathrm{~s}$, and the damping factor is 0.1 . The governor frequency droop is 0.05 pu.

Three different scenarios are simulated and results, as power and frequency deviations, are presented and discussed.

\section{A. Scenario I}

In this case study, converter A operates with power-voltage droop and converter B with constant power. A load of 400 MW is switched on in onshore A and causes a frequency drop. Support from HVDC is expected. The supportive power is expected to be supplied from both of the WPPs. Different simulation results for this scenario are shown in Fig. 6, 7, 8 and 9. Four different cases are simulated. Case A, with no support from HVDC; Case B, using communication links; Case, without communication link; Case $\mathrm{D}$, without communication links, but droop is compensated on onshore A converter.

As shown in Fig. 6 frequency support without using communication link is not as effective as in the case of using communication links. When the communication-less method is compensated, Case D, on onshore A, the frequency support can be ideal (i.e., similar to that of using communication link), 


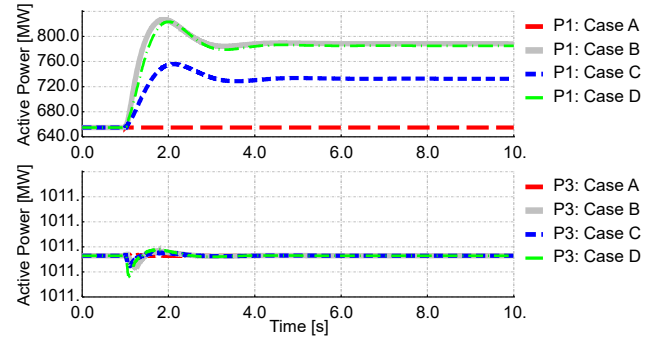

Fig. 8. Active power of onshore converters when a load increases on onshore A.

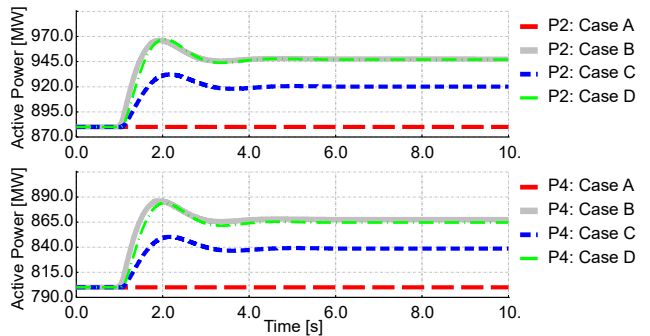

Fig. 9. Active power of WPPs when a load increases on onshore A.

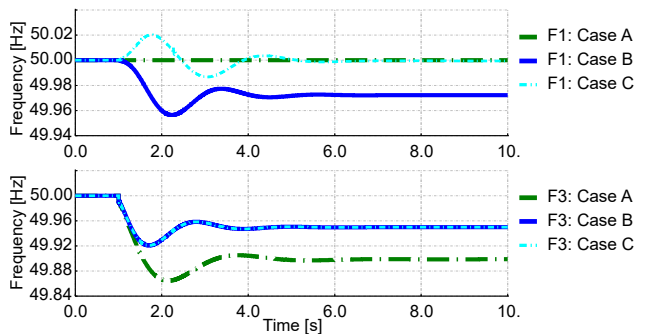

Fig. 10. Frequency of onshore ac grids when a load increases on onshore B

however, with different frequency drops on offshore ac systems as shown in Fig. 7.

\section{B. Scenario II}

Converter controllers are the same as those in the previous scenario. In this scenario, it is assumed that $400 \mathrm{MW}$ load is increased in onshore B and frequency support is implemented with two different methods; with and without using communication links. Three case studies are simulated: Case A with no support from HVDC; Case B, without communication link; Case $\mathrm{C}$, using communication. The simulation results for this scenario are shown in Fig. 10, 11, 12 and 13. It is clear that the frequency support with and without using communication have the same result. This is because the converter B operates with constant power and there is no interaction between droops. In this scenario, the difference between frequency support with and without communication link is that in the former case the supportive power is supplied only from WPPs but in the latter, the onshore A also contributes in the support. As shown in Fig. 13, when implementing the frequency support using communication link, the active power of offshore $\mathrm{C}$ reaches to its limit which is $1000 \mathrm{MW}$.

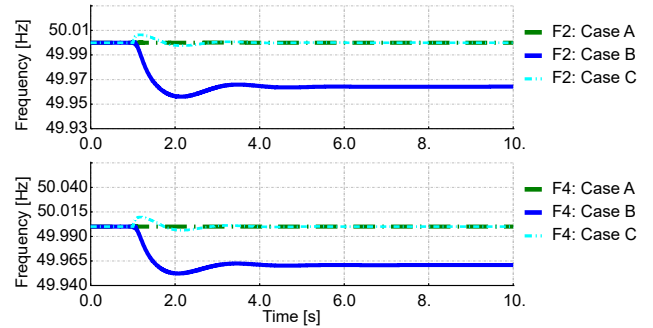

Fig. 11. Frequency of offshore ac grids when a load increases on onshore B.

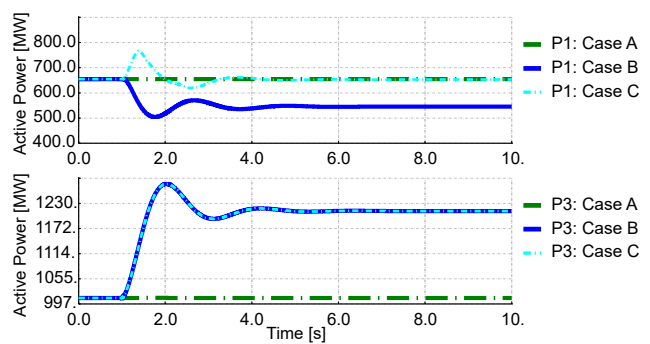

Fig. 12. Active power of onshore converters when a load increases on onshore B.

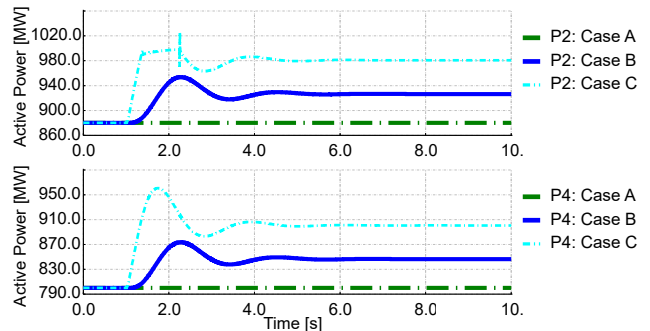

Fig. 13. Active power of WPPs when a load increases on onshore B.

\section{Scenario III}

In this scenario, both onshore converters operate with power-voltage droop control. It is assumed that a load change happens in system A and its frequency drops. Simulation results for this scenario are shown in Fig. 14, 15, 16 and 17. There are four different simulation cases. Case A, both onshore converters are equipped with frequency droop control and support is provided to system A without communication links; Case B, communication links are used between system A and both WPPs; Case C, there are communication links and frequency control on converter B is deactivated; Case D, the frequency support without communication link has been compensated. Like the previous scenario when using communication and importing all required supportive power only from WPPs, offshore $\mathrm{C}$ reaches its limit. In other cases, this phenomena does not happen since a part of supportive power is supplied from another onshore system, and consequently, the offshore WPPs are not overloaded.

\section{CONCLUSIONS}

The primary frequency support from HVDC connected offshore wind power plants is investigated with and without using communication links between onshore and offshore 


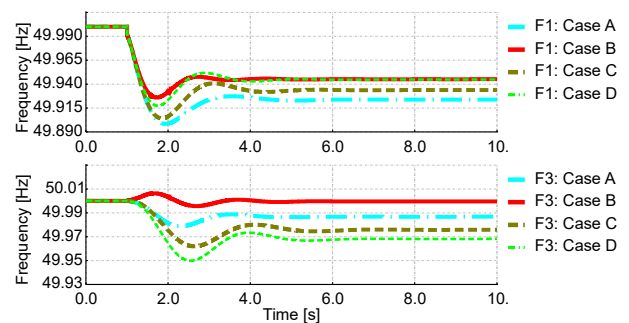

Fig. 14. Frequency of onshore ac grids when both onshore converters operate with droop control, and a load increases on onshore A.

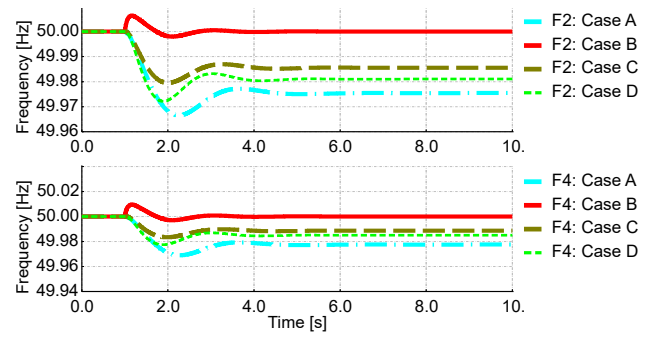

Fig. 15. Frequency of offshore ac grids when both onshore converters operate with droop control, and a load increases on onshore A.

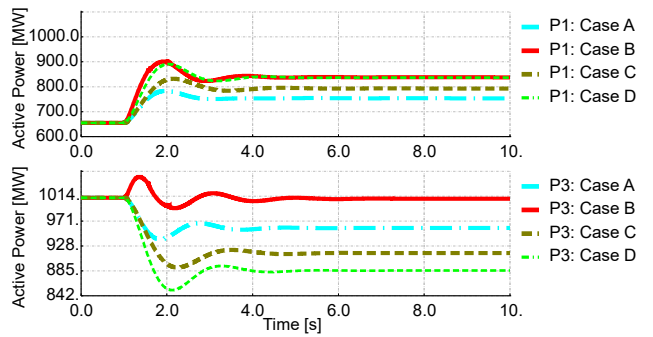

Fig. 16. Active power of onshore converters when both onshore converters operate with droop control, and a load increases on onshore A.

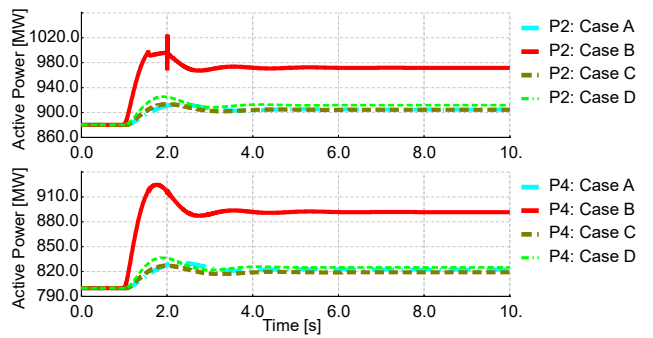

Fig. 17. Active power of WPPs when both onshore converters operate with droop control, and a load increases on onshore A.

systems. In the communication-less scheme, power-voltage droop interacts with frequency-power droop and results in inefficient frequency support, which should be compensated to satisfy the corresponding grid code requirement. It was shown that in the case of HVDC grid with more than one onshore ac system, the compensation is not easy, as the ac system parameters such as damping factor and governor gain are needed. A static model was proposed to ease the calculations required for compensation. It was also shown that in the case of communication-less frequency support of one onshore system, power flow and frequency of another onshore with voltage droop control can be affected. This implies that the system operators of onshore grids connected to the same HVDC network should agree on power-sharing in the case of frequency deviation of each power system.

\section{REFERENCES}

[1] G. Lalor, A. Mullane, and M. O'Malley, "Frequency Control and Wind Turbine Technologies," IEEE Transactions on Power Systems, vol. 20, no. 4, pp. 1905-1913, Nov. 2005.

[2] H. T. Ma and B. H. Chowdhury, "Working towards frequency regulation with wind plants: Combined control approaches," IET Renewable Power Generation, vol. 4, no. 4, pp. 308-316, Jul. 2010.

[3] Y. G. Rebours, D. S. Kirschen, M. Trotignon, and S. Rossignol, "A Survey of Frequency and Voltage Control Ancillary Services-Part I: Technical Features," IEEE Transactions on Power Systems, vol. 22, no. 1 pp. 350-357, Feb. 2007.

[4] A. Bidadfar, O. Saborío-Romano, M. Altin, Ö. Göksu, N. A. Cutululis, and P. E. Sørensen, "Offshore wind farms and HVDC grids modeling as a feedback control system for stability analysis," in 16th Wind Integration Workshop, Berlin, Germany, 25-27 Oct. 2017.

[5] Y. Phulpin, "Communication-Free Inertia and Frequency Control for Wind Generators Connected by an HVDC-Link," IEEE Transactions on Power Systems, vol. 27, no. 2, pp. 1136-1137, May 2012.

[6] F. D. Bianchi, J. L. Domínguez-García, and O. Gomis-Bellmunt, "Control of multi-terminal HVDC networks towards wind power integration: A review," Renewable and Sustainable Energy Reviews, vol. 55, pp. 1055 - 1068, Mar. 2016

[7] A. D. Hansen, M. Altin, I. D. Margaris, F. Iov, and G. C. Tarnowski, "Analysis of the short-term overproduction capability of variable speed wind turbines," Renewable Energy, vol. 68, no. 1, pp. 326 - 336, Aug. 2014.

[8] J. N. Sakamuri, M. Altin, A. D. Hansen, and N. A. Cutululis, "Coordinated frequency control from offshore wind power plants connected to multi terminal DC system considering wind speed variation," IET Renewable Power Generation, vol. 11, no. 8, pp. 1226-1236, Jun. 2017.

[9] B. Silva, C. L. Moreira, L. Seca, Y. Phulpin, and J. A. Peças-Lopes, "Provision of Inertial and Primary Frequency Control Services Using Offshore Multiterminal HVDC Networks," IEEE Transactions on Sustainable Energy, vol. 3, no. 4, pp. 800-808, Oct. 2012.

[10] I. Martínez-Sanz, B. Chaudhuri, and G. Strbac, "Inertial Response From Offshore Wind Farms Connected Through DC Grids," IEEE Transactions on Power Systems, vol. 30, no. 3, pp. 1518-1527, May 2015.

[11] T. M. Haileselassie and K. Uhlen, "Primary Frequency Control of Remote Grids Connected by Multi-terminal HVDC," in IEEE PES General Meeting, Providence, RI, United States, 25-29 Jul. 2010.

[12] S. Akkari, J. Dai, M. Petit, and X. Guillaud, "Interaction between the voltage-droop and the frequency-droop control for multi-terminal HVDC systems," IET Generation, Transmission \& Distribution, vol. 10, no. 6, pp. 1345-1352, Apr. 2016.

[13] T. Joseph, J. Gonçalves, C. E. Ugalde-Loo, and J. Liang, "WindThermal Generation Coordination in Multi-Terminal HVDC-Connected AC Systems for Improved Frequency Support," in 13th IET International Conference on AC and DC Power Transmission (ACDC 2017), Manchester, United Kingdom, 14-16 Feb. 2017, pp. 1-6.

[14] O. Saborío-Romano, A. Bidadfar, Ö. Göksu, and N. A. Cutululis, "Frequency Support from OWPPs connected to HVDC via Diode Rectifiers," in 16th Wind Integration Workshop, Berlin, Germany, 25-27 Oct. 2017.

[15] A. Bidadfar, O. Saborío-Romano, M. Altin, N. A. Cutululis, P. E. Sørensen, E. Prieto-Araujo, and O. Gomis-Bellmunt, "Frequency support provision to power systems via hvdc-based offshore wind power plants," in 17th Wind Integration Workshop, Stockholm, Sweden, 17-19 Oct. 2018.

[16] E. Muljadi, S. Pasupulati, A. Ellis, and D. Kosterov, "Method of Equivalencing for a Large Wind Power Plant with Multiple Turbine Representation," in 2008 IEEE Power and Energy Society General Meeting - Conversion and Delivery of Electrical Energy in the 21st Century, Chicago, IL, United States, 20-24 Jul. 2008.

[17] N. Chaudhuri, B. Chaudhuri, R. Majumder, and A. Yazdani, MultiTerminal Direct-Current Grids: Modeling, Analysis, and Control. Hoboken, NJ, United States: John Wiley \& Sons, Oct. 2014. 